\title{
Psychological Treatments for Depression An Update
}

\author{
JAN SCOTT
}

There is robust evidence for the efficacy of pharmacotherapy in the treatment of depressive disorders (Paykel \& Priest, 1992). However, patient preferences for non-drug therapies, contraindications to pharmacotherapy, the nature of the presentation (particularly Axis II comorbidity), failure to respond to medication and non-compliance with antidepressants have all contributed to the increased interest in psychological treatments for depression. As well as the need for these alternatives to be costeffective, Howard et al $(1986,1989)$ identify clinical and pragmatic reasons for promoting short-term (about 20 sessions) interventions. Firstly, at least $66 \%$ of the therapeutic gain accrues in the first 20-25 sessions. Secondly, the median number of sessions attended by individuals receiving out-patient psychotherapy in the USA is 14. The need to improve on the 'dose-effect' curve and to work within the limitations of the average length of a course of therapy has focused attention on the so-called 'manualised' therapies for depression, namely behaviour therapy (BT), cognitive therapy (CT), interpersonal therapy (IPT) and brief dynamic psychotherapy (BDP). These are time-limited, 'here and now' therapies that primarily target symptom or problem resolution rather than personality change (United States Department of Health \& Human Sciences (US DHHS), 1993). This paper gives a brief update on these treatment models, identifies therapy characteristics that may contribute to efficacy and highlights some questions that still need to be answered.

\section{Psychological approaches to depression}

\section{Behaviour therapy}

The most frequently practiced models of BT are selfcontrol therapy (Rehm, 1979) and social skills training (Bellack et al, 1983). Most BT packages are derived from social learning theory (Bandura, 1977) which assumes that depression and reinforcement are related phenomena and also that social skills deficits may contribute to the inability to obtain available positive reinforcers and/or cope with adversity (Lewinsohn et al, 1982). There are four core elements in BT for depression: functional analysis, daily monitoring and then planning of activities, managing aversive experiences and developing social skills.

\section{Cognitive therapy}

At least eight models of cognitive therapy (CT) are described (Scott, 1994), but the most widely researched is Beck's approach $(1976,1983)$. Most depressed people express 'negative automatic thoughts' about themselves, their world and their future. Beck noted that these negative cognitions are sustained through faulty information processing and so a vicious cycle is set up in which low mood increases the intensity of negative thinking which increases affective, cognitive and behavioural disturbance. These negative cognitions may arise from the re-activation of dysfunctional underlying beliefs. The essential characteristic of CT is its use of a collaborative, 'hypothesistesting' approach (Beck et al, 1979). The acute symptoms of depression are tackled through the use of behavioural and verbal techniques (identifying and challenging negative cognitions). Later interventions are targeted at challenging dysfunctional beliefs to try to reduce vulnerability to future episodes.

\section{Interpersonal therapy}

Klerman et al (1984) hypothesise that interpersonal problems may be a cause or consequence of depression. Interpersonal therapy aims to reduce the acute symptoms of depression and recognise and resolve associated role impairment in one or more of four problem areas: prolonged grief reactions, role disputes, role transitions and interpersonal deficits. The approach targets current problems and feelings and also aims to reduce relapse. It draws on familiar techniques such as education and clarification plus interventions aimed at improving interpersonal communication and social skills (Cornes, 1990). Given the appeal and efficacy of IPT it is surprising that it is not more widely available in Britain. 


\section{Brief dynamic psychotherapy}

These therapies are firmly grounded in psychoanalytic principles and the disorder is viewed in terms of adaptive failure resulting from inner conflicts (Strupp et al, 1982). Rather than targeting depressive symptoms per se, the goal of BDP is to use the therapeutic relationship to clarify and explore neurotic conflicts (such as problems of intimacy or relatedness). Several different brief therapy models have been published (Luborsky, 1984; Strupp \& Binder, 1984; Ryle, 1990). The approaches share one or more of the following characteristics (Strupp et al, 1982; Worchel, 1990): therapy is focused on a central theme such as loss or separation, early sessions are used to assess and select highly motivated individuals, extensive use is made of transference interpretations, and grief and anger about therapy termination are worked through.

\section{Outcome studies}

The majority of psychotherapy outcome studies in depression focus on CT, a smaller number investigate BT and IPT and relatively few examine BDP (Hollon et al, 1993; Karasu, 1993; Scott, 1994; Weissman, 1994). Methodological problems such as inadequate sample size are common, but the major flaw in most studies is the lack of a pill-placebo control. The only acute study to rectify this (Elkin et al, 1989) was incorporated into the most recent 'intent-to-treat' metaanalysis (US DHHS, 1993). Outcome data from 28 carefully selected randomised controlled trials of group and individual therapy for major depressive disorder were defined in categorical (recovered; not recovered) terms. It was found that the efficacy of individual CT (response rate $=50 \%$ ), BT $(55 \%)$ and IPT $(52 \%)$ in the treatment of the acute episode were not significantly different and compared favourably with pharmacotherapy $(58 \%)$. Brief dynamic psychotherapy was less potent $(35 \%)$. Whether the lack of a specific depression treatment model or the preponderance of group rather than individual BDP studies had an adverse effect on outcome is unclear. Cognitive therapy is less effective in a group format $(39 \%)$, BT is equally effective, while IPT may be more beneficial if a 'significant other' takes part.

Data on whether the use of a combination of psychotherapy and pharmacotherapy is advantageous are inconclusive. No studies are available on BDP, and meta-analytic data from eight outcome studies $(C T=5)$ suggest that neither CT, BT or IPT plus antidepressants are any more effective than pharmacotherapy alone (US DHHS, 1993). However, Hollon et al (1993) found a non-significant trend for greater symptomatic improvement (an increment of $15 \%$ in absolute terms) in those with more severe disorders receiving a combination of pharmacotherapy and CT as opposed to either treatment alone.

There are few adequately designed follow-up or maintenance treatment studies examining the role of psychotherapy in the prevention of relapse of depression. None are available on BDP and there are no maintenance treatment studies of BT. Follow-up studies of BT (Hersen et al, 1984; McLean \& Hakstian, 1990) and IPT (Weissman et al, 1981) do not demonstrate any significant differences in outcome between these interventions and the other psychological or drug treatments with which they were compared. However, there is evidence from a well-designed three year study of maintenance IPT (undertaken at monthly intervals) that IPT alone may significantly delay the onset of relapse in those individuals not receiving antidepressant medication (Frank et al, 1990). Blackburn et al (1986) undertook a study of maintenance CT (about five sessions in the six months following acute treatment). At two year follow-up, the relapse rate in patients who had received pharmacotherapy $(\mathbf{7 2 \%})$ was significantly higher than that in patients who had received CT either alone or in combination with drugs $(22 \%)$. Other publications suggest a possible role for CT in preventing relapse $(n=7)$, but interpretation is hampered because they consist of naturalistic followups of treatment responders from acute depression studies. An exception is Evans et al's study (1992) which comprises a follow-up of a cohort of patients treated in a randomised control trial of CT and pharmacotherapy (Hollon et al, 1992). The relapse rate in the CT group (20\%) was non-significantly lower than that in the drug continuation treatment group (27\%) but was less than half that of the group whose drug treatment was withdrawn when their depressions remitted $(50 \%)$.

\section{Common factors in effective therapies}

Reviewing the IPT, BT and CT models of treatment for depression (BDP manuals are not disorder specific), it is possible to identify certain features that may help explain why they are effective (Zeiss et al, 1977; Kornblith et al, 1983; Teasdale, 1985; Scott, 1994): the individual is provided with an understandable model of depression; each therapy has a wellplanned rationale and is highly structured; plans for producing change are made in logical sequences; therapy encourages independent use of skills to promote change; change is attributed to the individual's rather than the therapist's skilfullness and importantly, the individual develops a greater sense of self-efficacy. 
It can be hypothesised that how the patient and therapist relate to the model will play an important role. Research confirms that patient attitudes and quality (rather than quantity) of therapy significantly influence outcome. The patient's belief in the model of depression advocated and their expectation that they will benefit both predict treatment response (Sotsky et al, 1991; Scott, 1994). The therapist's level of skill and adherence to the treatment model are also significant factors accounting for up to $30 \%$ of the variance in outcome (Marziali, 1984; O'Malley et al, 1988; DeRubeis \& Feeling, 1990; Hollon et al, 1993).

\section{Conclusions}

If the patient or clinician wishes to pursue a psychological alternative, which therapy is to be recommended? The US DHHS (1993) report suggests that in the first instance clinicians should choose a 'manualised' therapy that has an established record for efficacy in randomised controlled clinical trials. While this is sound advice, the meta-analysis reported earlier suggested that BT, IPT and CT were equally effective. Unfortunately, we do not know whether individuals who respond to one approach will also respond to other interventions. Studies aimed at identifying specific predictors have failed to produce consistent findings (Sotsky et al, 1991; Scott, 1994). This is a crucial question for future research, as knowledge about which patients respond to which treatment in which particular setting (Clark, 1989) will allow interventions to be targeted more systematically. In the interim, the four most pragmatic considerations are: the severity of the disorder, the patient's preference, the nature of any psychosocial difficulties and the availability of a trained therapist.

In mild to moderately severe unipolar depressions, a psychological or pharmacological approach may be effective and, provided a 'manualised' therapy is available, patient preference may largely dictate choice. If a patient with a severe depressive episode (crudely defined by a Hamilton score $>21$ ) requests psychotherapy, it should generally be combined with antidepressant medication as the research evidence (although inconsistent) suggests that a 'manualised' therapy alone may not be sufficient (US DHHS, 1993). Specific indications for the use of psychotherapy as an adjunct to pharmacotherapy are underresearched, although clinicians identify potential benefits from combined therapies in chronic disorders or in cases with co-existent Axis II or other long-term psychological problems (Manning \& Frances, 1990).
The fact that psychological treatments can be as effective as antidepressants in alleviating acute depression is not in itself a reason to extend their use, particularly as time and cost considerations tend to favour the use of pharmacotherapy. Greater emphasis on health gain and relapse prevention may increase the use of psychological treatments and, in this context, the efficacy of IPT and CT as alternative maintenance treatments is noteworthy. However, for psychotherapy to be promoted more actively controlled larger scale research studies must replicate the findings of Evans et al (1992). At present, research support for the idea that psychotherapy has a more durable effect is inconclusive, but the potential importance of these results is highlighted by Hollon et al (1993). They noted that if the risk of depressive relapse after completing a course of CT is reduced to the same level as that of patients continuing to receive maintenance pharmacotherapy it will be the first time any form of antidepressant treatment has been shown to have an effect beyond the point of termination of the intervention. It would also provide a cogent clinical and economic argument for greater accessibility to 'manualised' treatment models.

This paper is based on a presentation given at the Joint Meeting of the Czech Psychiatric Association and the Royal College of Psychiatrists, in Prague, November 1994.

\section{References}

BANDURA, A. (1977) Self-efficacy: Toward a unifying theory of behavioural change. Psychological Review, 84, 191-215.

Beck, A. T. (1976) Cognitive Theory and the Emotional Disorders, pp. 47-132. New York: International Universities Press.

- (1983) Cognitive therapy of depression: New perspeetives.

In Treatment of Depression: Old Controversies and New Approaches (eds P. Clayton \& J. Barrett), pp. 265-284. New York: Raven Press.

-, Rush, A. J., Shaw, B. F., et al (1979) Cognitive Therapy of Depression. New York: Guilford Press.

Bellack, A., Hersen, M. \& Harmondsworth, J. (1983) Social skills training compared with pharmacotherapy and psychotherapy for depression. Behaviour Research and Therapy, 21, 101-107.

Blackburn, I., Euson, K. \& Bishop, S. (1986) A two year naturalistic follow-up of depressed patients treated with cognitive therapy, pharmacotherapy or both. Journal of Affective Disorders, 10, 67-75.

ClaRK, D. (1989) Cognitive therapy for depression and anxiety: Is it better than drug treatment in the long term? In Dilemmas and Difficulties in the Management of Psychiatric Patients (eds K. Hawton \& P. Cowen), pp. 52-96. Oxford: Oxford University Press.

CORNes, C. (1990) Interpersonal psychotherapy of depression. In Handbook of Brief Psychotherapies (eds R. Wells \& V. Giannetti), pp. 261-276. New York: Plenum Press.

DeRubeis, R. \& Feeling, M. (1990) Determinants of change in cognitive therapy of depression. Cognitive Therapy and Research, 14, 469-482. 
Elkin, I., SheA, M., Watkins, J., et al (1989) National Institute of Mental Health Treatment of Depression Collaborative Treatment Programme. Archives of General Psychiatry, 46, 971-982.

Evans, M., Hollon, S., DeRubeis, R., et al (1992) Differential relapse following cognitive therapy and pharmacotherapy for depression. Archives of General Psychiatry, 49, 802-808.

Frank, E., Kupfer, D., Perel, J., et al (1990) Three year outcomes for maintenance therapies in recurrent depressions. Archives of General Psychiatry, 47, 1093-1099.

Hersen, M., Bellack, A., Himmelhoch, J., et al (1984) Effects of social skills training, amitryptiline and poychotherapy on unipolar depressed women. Behaviour Therapy, 15, $21-40$.

Hollon, S., DeRubeis, R., Evans, M., et al (1992) Cognitive therapy and pharmacotherapy for depression: singly and in combination. Archives of General Psychiatry, 49, 774-781.

, Shelton, R. \& DAvis, D. (1993) Cognitive therapy for depression: Conceptual issues and clinical efficacy. Journal of Consulting and Clinical Psychology, 2, 270-275.

Howard, K., Kopta, S., Krause, M., et al (1986) The dose-effect relationship in psychotherapy. American Psychologist, 41, 159-164.

_, Davidson, C., O'Mahoney, M., et al (1989) Patterns of psychotherapy utilization. American Journal of Psychiatry, 146, 775-778.

KARASU, T. (1993) Depression: the relative merits of pharmacotherapy and psychotherapy. Current Opinion in Psychiatry, 6, 184-190.

Klerman, G., Weissman, M., Rounsaville, B., et al (1984) Interpersonal Psychotherapy. New York: Basic Books.

Kornblith, S., Rehm, L., O'HarA, M., et al (1983) The contribution of self-reinforcement training and behavioural assignments to the efficacy of self-control therapy for depression. Cognitive Therapy and Research, 6, 499-528.

Lewinsohn, P., Sullivan, J. \& Grosscup, S. (1982) Behaviour therapy: Clinical applications. In Short-term Psychotherapies for Depression (ed. A. J. Rush), pp. S0-87. Chichester: Wiley.

Luborsxy, L. (1984) Principles of Psychoanalytic Psychotherapy. New York: Basic Books.

MANNing, D. \& Frances, A. (1990) Combined Pharmacotherapy and Psychotherapy for Depression. Washington: American Psychiatric Association.

Marziali, E. (1984) Three viewpoints on the therapeutic alliance. Journal of Nervous and Mental Diseases, 7, 417-423.
Mclean, P. \& Hakstian, A. (1990) Relative endurance of unipolar depression treatment effects: Longitudinal follow-up. Journal of Consulting and Clinical Psychology, 58, 482-488.

O'Malley, S., Foley, S. \& Rounsaville, B. (1988) Therapist competence and patient outcome in interpersonal psychotherapy of depression. Journal of Consulting and Clinical Psychology, 56, 496-501.

PAykel, E. S. \& Priest, R. (1992) Recognition and management of depression in general practice: consensus statement. British Medical Journal, 305, 1198-1202.

ReHM, L. (1979) Behaviour Therapy for Depression. New York: Academic Press.

Ryue, A. (1990) Cognitive-Analytic Therapy: Active Participation in Change. Chichester: Wiley.

SCorT, J. (1994) Cognitive therapy of depressive disorders. Current Opinion in Psychiatry, 7, 233-236.

Strupp, H., Sandell, J., Waterhouse, G., et al (1982) Psychodynamic therapy: Theory and research. In Short-term Psychotherapies for Depression (ed A. J. Rush), pp. 215-250. Chichester: Wiley.

- \& Binder, J. (1984) Psychotherapy in a New Key. New York: Basic Books.

Sorsky, S., Glass, D., Shea, M., et al (1991) Patient predictors of response to psychotherapy: Findings in the NIMH treatment of depression collaborative research programme. American Journal of Psychiatry, 148, 997-1008.

Teasdale, J. (1985) Psychological treatments of depression: how do they work? Behaviour Research and Therapy, 23, 157-165.

US Departmant of Health \& HUMAN SCIENCES (US DHHS) (1993) Depression in Primary Care: Treatment of Major Depression, pp. 71-123. Depression Guideline Panel. Rockville: AHCPR Publications.

Weissman, M. (1994) Psychotherapy in the maintenance of depression. British Journal of Psychiatry, 165 (suppl. 26), 42-50.

-, Klerrman, G., Prusofr, B., et al (1981) Depressed outpatients: Results one year after treatment with drugs and/or interpersonal psychotherapy. Archives of General Psychiatry, 38, 51-55.

Worchier, J. (1990) Short-term dynamic poychotherapy. In Handbook of Brief Psychotherapies (eds R. Wells \& V. Giannetti), pp. 193-216. New York: Plenum Press.

Zeiss, A., Lewinsohn, P. \&unoz, R. (1977) Non-specific improvement effects in depression using interpersonal skills training, pleasant activity schedules, or cognitive training. Journal of Consulting and Clinical Psychology, 47, 427-439.

Professor Jan Scott, FRCPsych, University Department of Psychiatry, Royal Victoria Infirmary, Newcastle upon Tyne NE1 4LP. Fax (0191) 2275108

(First received 26 January 1995, final revision I February 1995, accepted 10 March 1995) 